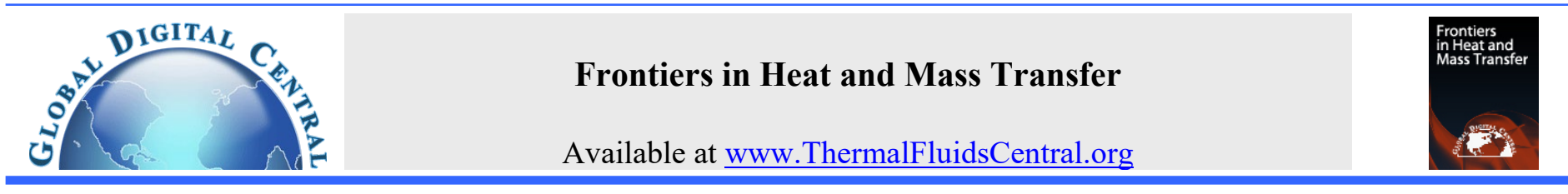

\title{
LITHIUM-ION BATTERY FIRE SUPPRESSION USING WATER MIST SYSTEMS
}

\author{
Matt Ghiji ${ }^{\mathrm{a},}$, Ian Burch ${ }^{\mathrm{b}}$, Brigitta Suendermann ${ }^{\mathrm{b}}$, Grant Gamble ${ }^{\mathrm{b}}$, Vasily Novozhilov ${ }^{\mathrm{a}}$, Paul Joseph ${ }^{\mathrm{a}}$, Khalid Moinuddin ${ }^{\mathrm{a}}$ \\ ${ }^{a}$ Institute of Sustainable Industries and Liveable Cities (ISILC), Werribee Campus, Victoria University, PO Box 14428, Melbourne, VIC, 8001, \\ Australia \\ ${ }^{b}$ Maritime Division, Defence Science \& Technology Group, 506 Lorimer St, Fishermans Bend, Melbourne, VIC, 3207, Australia
}

\begin{abstract}
Lithium-ion batteries (LiBs) have superior energy density and lifetime compared to battery technologies such as lead acid. Despite the widespread application of LiBs in energy storage systems, electronic devices, aerospace and the automotive industry, they present a fire risk. In this study, experiments were conducted to characterize the thermal behavior of the electrolyte (as the main contributor to LiB fires) using a cone calorimeter; investigate the interactions of water mist and a Bunsen burner, as a precursor to examining the effectiveness of a water mist suppression system in extinguishing a LiB fire. In the present work, we have endeavored to systematically study the fire suppression efficacy of water mist by adopting to some novel approaches. This involved carefully planned laboratory scale explorations that involved a propane gas fueled flame, and subsequently by using bespoke set up that mimicked fire owing to fuel surge from typical Li-ion cell (18650 cells). In the latter set of fire suppression tests, water droplets were produced by a fan nozzle and sprayed horizontally toward the jet flame of replica 18560 battery containing only the electrolyte. The results showed that both fire types (Bunsen burner and $\mathrm{LiB}$ ) are suppressed rapidly on activation of the water mist fire suppression system for geometries that enable the water mist direct access to the lift-off zone, between the gas source and base of the flame.
\end{abstract}

Keywords: Lithium-ion Battery; Thermal Runaway; Fire; Suppression; Water Mist.

\section{INTRODUCTION}

The increased use of renewable energy technologies has put battery energy storage solutions in the spotlight. Lithium-ion batteries (LiBs) provide outstanding energy density, voltage and lifetime compared to other battery technologies (Blum and Long Jr 2016). In addition, LiBs are lightweight and have a low self-discharge rate making them the preferred battery technology for electronic handhelds, electric vehicles, and energy storage systems in airplanes and submarines (Pacala and Socolow 2004; Depetro 2016). Significant research has been conducted in the field of materials science to improve the energy density, safety, charge/discharge rate and longevity of LiBs.

A lithium-ion cell comprises an anode and cathode deposited onto copper and aluminum current collectors respectively, electrolyte and a separator. Lithium ions are transferred from the anode to the cathode during discharge and from the cathode to the anode during the charging process (Tarascon and Armand 2001; Galatro et al. 2020). The most common material used for the anode is graphite due to its high negative potential, and various lithium metal oxides are used for the cathode with lithium iron phosphate commonly recognized as the best compromise for energy output and safety. A Solid-Electrolyte-Interface (SEI), a layer permeable to lithium ions but not to the electrolyte, is formed on the anode due to reactions between intercalated lithium ions and the electrolyte during the initial charge. Intercalation is the reversible insertion of a molecule or ion into materials with layered structures. The stability and characteristics of the SEI layer determine LiB thermal behavior, safety and lifetime. LiB electrolyte is usually a flammable carbonate-based organic solvent, unlike other battery chemistries such as lead-acid, nickel-cadmium, zinc bromide and alkaline. However, the composition of the electrolyte may be varied to be compatible with the cathode and anode materials, with additives to improve cycling and lithium ion conductivity. Fire retardants may also be added to terminate the radical chain reactions of combustion, providing a safer operating environment (Julien et al. 2016; Ouyang et al. 2019). The separator is a porous membrane between the cathode and anode allowing lithium ion movement but preventing electrical short-circuiting between the anode and cathode (Julien et al. 2016; Arora and Zhang 2004). The separator materials are microporous films or laminates made of polyolefins such as polyethylene (PE) and polypropylene (PP).

Despite the widespread application of LiBs, there are major safety concerns especially in battery-based power storage station, personal electronic devices, electric vehicles (Ruiz et al. 2018) and airplanes (Rodriguez 2013). These battery systems consist of a large number of cells where a failure such as thermal runaway in a single cell can influence neighboring cells and consequently the safety of the entire battery system (Lamb et al. 2015). Thermal runaway is a process where an increase in temperature causes internal reactions that are exothermic and result in further increases in temperature, generally leading to battery venting and fire. Pressure relief vents are built into the lid of the battery casings to control overpressure and avoid explosion by directing venting gases, and possible jet fire, away from the battery module. The likelihood and consequence of $\mathrm{LiB}$ fires can be seen over the past two decades where more than 300 fires or fire-related incidents with 40 fatalities have been reported (Depetro 2016).

The abuse conditions which can initiate thermal runaway are categorized by: electrical abuse (over-charging/over-discharging) (Ye et al. 2016); thermal abuse (over-temperature) (Guo et al. 2017); 
mechanical abuse (Ruiz et al. 2018) and internal short circuit (Feng et al. 2018). Thermal runaway is associated with the occurrence of a variety of reactions involving the SEI decomposition, anode and electrolyte reactions and electrolyte decomposition (Wang et al. 2012; Ghiji, Edmonds, and Moinuddin 2021). The heat generated from the reactions can propagate to surrounding cells which may result in thermal runaway, cell rupture, gas venting, fire and explosion in the entire battery pack (Feng et al. 2018). Therefore, fire protection measures can be taken at the cell, module, pack, system and compartment levels (Wilkens et al. 2017). The fire protection measures range from integrated internal fuses to prevent internal shorting, fire retardants (Feng et al. 2018), power and temperature management (Singh et al. 2021), module separation and enclosure cooling (Ouyang et al. 2019). Fig. 1 depicts the levels of fire protection from cell components to compartment level.

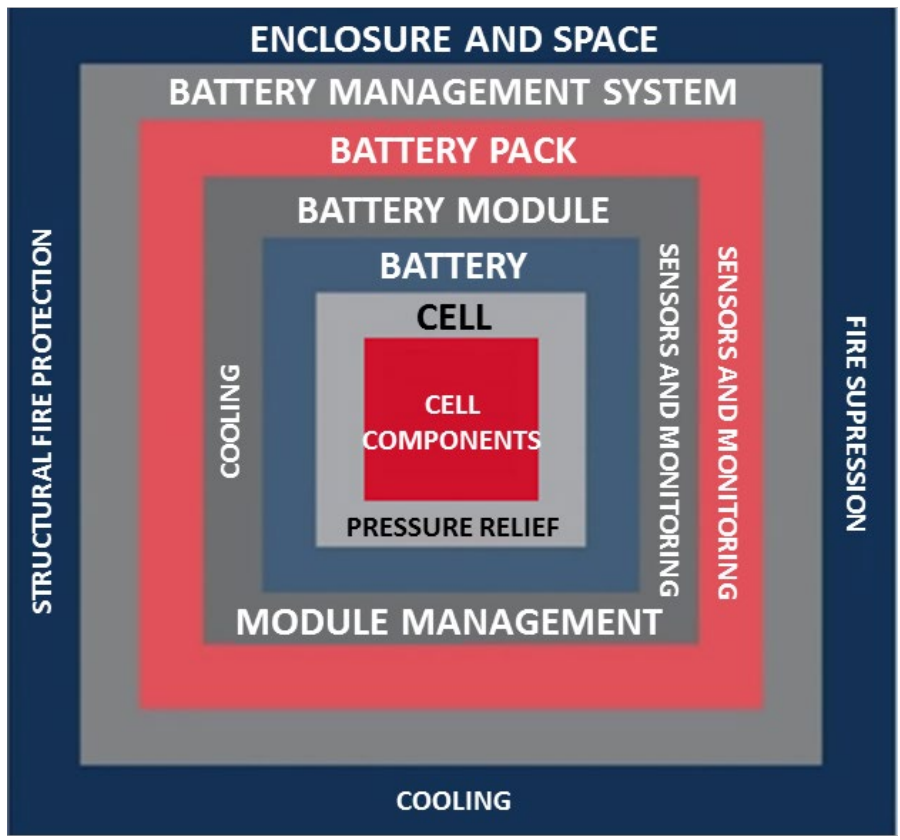

Fig. 1 The levels of fire protection for a LiB system in a compartment (Wilkens et al. 2017).

The classification of a LiB fire is controversial and can vary due to the complexity of battery components, but basically fits into classes A (fires in ordinary combustible materials, such as wood, cloth, paper, rubber, and many plastics), B (fires in flammable liquids, combustible liquids, petroleum greases, tars, oils, oil-based paints, solvents, lacquers, alcohols, and flammable gases), and $\mathrm{E}$ (fires that involve energized electrical equipment) (Kong et al. 2018; Ouyang et al. 2019). Many suppression systems, such as halogen-based gases, chemical powder and carbon dioxide can extinguish a LiB fire, but cannot maintain cooling to suppress thermal runaway (Summer 2010). If the LiB is not sufficiently cooled, thermal runaway may continue and the battery or its neighboring batteries may ignite (Ghiji et al. 2020).

Numerous researchers have studied $\mathrm{LiB}$ fires to examine fire suppression. The best practice and the optimum fire extinguishing medium for LiBs is yet to be determined (Summer 2010; Ditch and De Vries 2013). It has been reported by the US Federal Aviation Administration (FAA) (Maloney 2014) and US National Fire Protection Agency (NFPA) (Summer 2010) that halogen-based products can extinguish an open LiB fire, but cannot mitigate the internal battery temperature increase even after the extinguishment of a fire. In studies performed by Rao et al. (Rao et al. 2015), FM200 (heptafluoropropane) showed superior behavior in suppressing LiB fires compared to carbon dioxide and powder extinguishants. The effectiveness of FM200 in suppressing LiB fire was also reported by Wang et al. (Wang et al. 2016) while Liu et al (Liu et al. 2018) reported Novec 1230 to also be effective.

LiB fire suppression can also be achieved by applying large amounts of water to a battery or by submerging the battery in water (Hill 2017). Both of these methods extinguish LiB fires and cool the battery, inhibiting thermal runaway and preventing re-ignition. Det Norske Veritas and Germanischer Lloyd (DNV-GL) (Hill 2017) investigated the effectiveness of substances such as encapsulants (F500, FireIce, PyroCool), aerosol (Stat-X) and water sprinklers in suppressing a LiB fire and cooling a battery during thermal runaway. All systems extinguished the fires but the sprinkler system had enhanced continued cooling ability. Egelhaaf et al. (Egelhaaf et al. 2013) also demonstrated that the addition of surfactant and gelling agents can decrease the amount of water required for firefighting. Tests conducted by the FAA (Maloney 2014) concluded that water-based suppressants (water, Hartindo AF-31, Hartindo AF-21, Aqueous A-B-D) are more effective compared with non-aqueous extinguishants (Hill 2017). The Fire Protection Research Foundation (Long et al. 2013) through testing demonstrated that water mist can effectively suppress a fire involving an electric vehicle battery. It has also been reported that the extinguishing effect of water mist can be improved by adding 5\% F500 solution and 5\% anionic nonionic surfactant to pure water (Luo et al. 2018). The effectiveness of adding $3 \%$ aqueous surfactant to water mist on re-ignition of an 18650 type Lithium Cobalt Oxide battery pack $(10 \mathrm{Ah} \times 4)$ fire was analyzed by $\mathrm{Li}$ et al. (Li et al. 2015). It was shown that water mist with aqueous surfactant was more effective in delaying the re-ignition (45 seconds) compared to $\mathrm{ABC}$ powder (10 seconds), and carbon dioxide (8 seconds).

So far, water mist with additives such as surfactants and encapsulants (Luo et al. 2018) are considered to be promising for extinguishing and cooling LiBs. However, these additives could be harmful to the environment (Wang et al. 2019) and thus where possible water mist alone would be preferred. Water mist is considered due to its low water usage compared with other water-based suppression systems. However, further investigation on the thermal behavior of LiBs, firefighting strategies and suppression mediums are required to establish a preferred guideline to extinguish LiB fires.

There are typically five mechanisms associated with fire extinguishment using water mist in a closed compartment (Mawhinney, Dlugogorski, and Kim 1994): gas-phase cooling; oxygen depletion and flammable vapor dilution; wetting and cooling of the fuel surface; radiation attenuation; and kinetic effects. Generally, all mechanisms take place to some extent during the suppression of LiB fires in enclosures. Conventional water mist systems direct droplets downward. However in the present work, we have developed a novel technique, where a sheath of fine water droplets was deployed horizontally across the flame front. Prior to this set of experiments we also carried out some preliminary investigations using an in-house-built testing rig consisting of a water spray and fires generated by burning propane gas through a Bunsen burner set up. The results showed that fires are suppressed rapidly on activation of the mist systems where geometries and configurations of the effluent mist that were capable of affecting the lift-off zone, between the gas source and base of the flame.

\section{MATERIALS AND METHODS}

A LiB undergoing the process of thermal runaway shows multi-stage behavior including cell expansion stage, gas spill and auto-ignition stage, jet fire stage, and stable combustion stage (Wang et al. 2017). Depending on the state of charge of the LiB, additional smoking, jet fire, and combustion stages can occur. During thermal runaway in a $\mathrm{LiB}$, the electrolyte and separator may significantly contribute to heat release in the presence of oxygen through their ignition and combustion processes. Although the electrolyte and separator have low mass in a LiB, approximately $10 \%$ and $3 \%$ of the cell mass respectively (Ribière et al. 2012; Ping et al. 2015), they provide high effective heat of combustion and account for approximately $80 \%$ of the heat release in a LiB fire. As 
shown in Fig. 2, the effective heat of combustion for a commercial Lithium Manganese Oxide pouch cell was measured as $4.03 \pm 0.34 \mathrm{KJ} \mathrm{g}^{-1}$ with the electrolyte and separator contributing up to 1.92 , and $1.34 \mathrm{KJ} \mathrm{g}^{-1}$, respectively (Ribière et al. 2012).

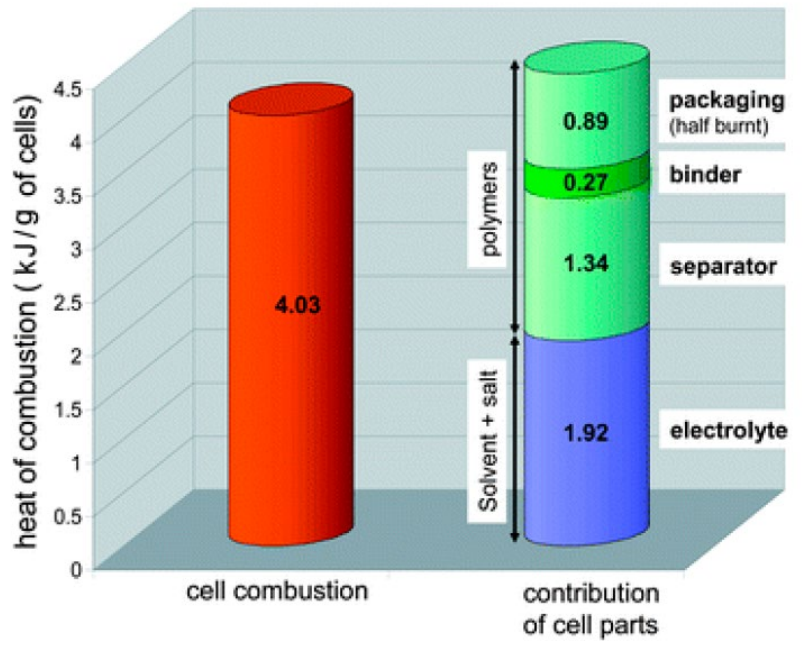

Fig. 2 Left: the total heat of combustion measured through experimentation. Right: heat of combustion of battery components determined by thermodynamic calculations (Ribière et al. 2012).

It is the unpredictability of the electrolyte reaction to heating that is the most difficult to define which enhance the complexity of a LiB fire event. Furthermore, the combustion characteristics of a $\mathrm{LiB}$ are influenced by its chemical composition, stored electrical energy and construction.

To simplify the fire process and eliminate the effect of other contributions to the combustion, a representative electrolyte only version of an 18650 (18 $\mathrm{mm}$ diameter by $65 \mathrm{~mm}$ length) $\mathrm{LiB}$ was developed as a replica cell. The replica cell concept can also be appreciated by Computational Fluid Dynamics analysis to evaluate and validate their simulation settings and results. A cylindrical steel rod was inserted into an empty 18650 cell case to fill the void taken by the battery internals, the case was filled with 5 grams of the electrolyte and the safety lid crimped onto the body. The replica battery contains the same mass of electrolyte as an $18650 \mathrm{LiB}$.

To examine water mist suppression of venting LiB fires, three sets of experiments were undertaken;

1. Characterization of the thermal behavior of the electrolyte,

2. Preliminary investigation of the interactions of water mist and simple (diffusion) flame using a Bunsen burner and various water mist nozzle configurations and

3. Examination of the behavior of $\mathrm{LiB}$ fires to water mist suppression.

\subsection{Thermal analysis of the electrolyte using a cone calorimeter}

The thermal properties of $\mathrm{LiB}$ electrolyte such as the heat release rate (HRR), and mass loss are measured using a cone calorimeter (Babrauskas et al. 2015) and a load cell similar to the tests conducted by Larsson et al. (Larsson et al. 2018; Larsson 2017; Larsson, Andersson, and Mellander 2016; Larsson et al. 2014). The HRR, considered the most important variable in fire hazard assessment (Babrauskas and Peacock 1992), is determined by the oxygen consumption principle, According to the oxygen consumption principle, each organic liquid, gas or solid releases approximately $13.1 \mathrm{MJ}$ heat per $\mathrm{kg}$ of consumed oxygen for complete combustion (Ping et al. 2015). The cone calorimeter tests conducted in this study are in conformance with ISO 5660 ("ReactionTo-Fire Tests; Heat Release, Smoke Production and Mass Loss Rate" 2015).
During these tests, 5 grams of electrolyte was poured into a stainless steel cup with a diameter of $52.5 \mathrm{~mm}$. The electrolyte was ignited after placing the cup under the cone calorimeter hood as shown in Fig. 3.

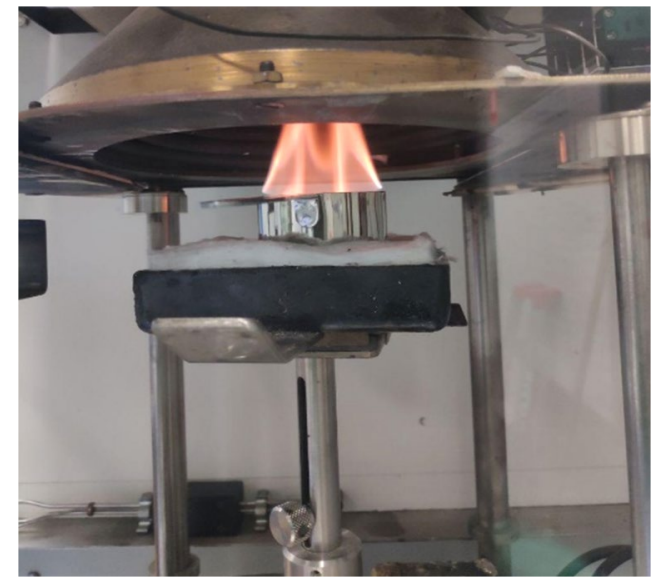

Fig. 3 Liquid sample fire under the cone Calorimeter.

The electrolyte investigated in this study is the most common electrolyte used in $\mathrm{LiBs}$, lithium hexafluorophosphate salts $\left(\mathrm{LiPF}_{6}\right)$ dissolved in ethylene carbonate (EC) and diethyl carbonate (DEC) (1.0 $\mathrm{M} \mathrm{LiPF}_{6}$ in $\mathrm{EC} / \mathrm{DEC}=50 / 50 \mathrm{v} / \mathrm{v}$ ) with a density of $1260 \mathrm{~kg} / \mathrm{m}^{3}$. The electrolyte was provided by Sigma-Aldrich Ltd Co. The electrolyte has a boiling point of $130{ }^{\circ} \mathrm{C}$ and a flashpoint of $30^{\circ} \mathrm{C}$. The operating conditions and settings of the cone calorimetry are described in Table 1.

Table 1 The cone calorimetry operating conditions and settings.

\begin{tabular}{|l|l|}
\hline Nominal duct flow rate $(\mathrm{l} / \mathrm{s})$ & 24 \\
\hline Initial mass $(\mathrm{g})$ & 5 \\
\hline Surface area of the cup $\left(\mathrm{cm}^{2}\right)$ & 21.65 \\
\hline Start and End of test criterion & ISO 5660-1:2002 \\
\hline Duct diameter $(\mathrm{m})$ & 0.114 \\
\hline Ambient temperature $\left({ }^{\circ} \mathrm{C}\right)$ & 25 \\
\hline Barometric pressure $(\mathrm{Pa})$ & 97000 \\
\hline Relative humidity $(\%)$ & 50 \\
\hline Heat flux $\left(\mathrm{kW} / \mathrm{m}^{2}\right)$ & 0 \\
\hline Sampling interval $(\mathrm{s})$ & 1 \\
\hline Orientation & Horizontal \\
\hline $\mathrm{O}_{2}$ delay time $(\mathrm{s})$ & 33 \\
\hline $\mathrm{CO}_{2}$ delay time $(\mathrm{s})$ & 15 \\
\hline $\mathrm{CO}$ delay time $(\mathrm{s})$ & 15 \\
\hline
\end{tabular}

\subsection{Interaction of water mist with a Bunsen burner flame}

To investigate the effectiveness of a water mist fire suppression system (WMFSS) in extinguishing $\mathrm{LiB}$ fires, the suppression system was initially tested using a propane gas Bunsen burner flame. Although the Bunsen burner presents premix combustion and a LiB shows non-premix combustion, the interactions of water mist droplets with flames are considered similar without the complexity of all the combustion processes of a LiB. The effects of different flame lengths and distances from the water mist nozzle to the burner tip on suppression time were examined. The flame length is measured using an image processing technique based on the intensity of flame similar to that presented by Zheng et al.(Zheng et al. 2011). Water was supplied to the nozzles at a pressure of 3.1 bar, generating droplet sizes in the range of $50-100 \mu \mathrm{m}$, according to Spray System Company manufacturer specifications. Two nozzles were used, each configured in a different orientation. The first nozzle was a conventional vertically-orientated brass single-hole hollow- 
cone nozzle with the orifice diameter of $1 \mathrm{~mm}$ and orifice length of $5 \mathrm{~mm}$, and flow rate 0.05 1/min, as shown in Fig. 4.

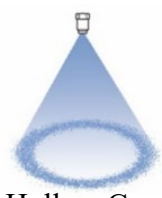

Hollow Cone Spray Pattern

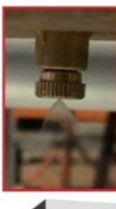

Nozzle

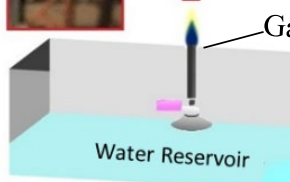

Fig. 4 Illustration of the vertically-orientated water mist apparatus for the small-scale fire test on a Bunsen burner flame; the single-hole hollowcone conical spray pattern is shown on the left.

The second nozzle was a stainless steel flat-fan nozzle with an equivalent orifice diameter of $0.66 \mathrm{~mm}$, and a flow rate of $0.521 / \mathrm{min}$ producing a spray angle of 110 degrees, oriented horizontally as shown in Fig. 5. The rationale behind the horizontal application of water mist is that it is applied directly to the combustion zone at the base of the flame rather than having to overcome the fire plume momentum. Although this strategy has been investigated computationally for various flame configurations (typical diffusion flame, stem of a rising fireball, and spread of flame front) (Karpov et al. 2004; Novozhilov 2003; Prasad, Li, and Kailasanath 1998a; Prasad, Li, and Kailasanath 1998b), to the best of the authors' knowledge, it has not been investigated for jet flame venting, as experienced in LiB fires. Similarly, a review of recent literature revealed no results on experimental work examining horizontal water mist effects on flame jet venting. Note that the efficacy of the two WMFSS nozzle orientations cannot be directly compared due to the different flow rates and spray dynamics; this comparison is for future works.

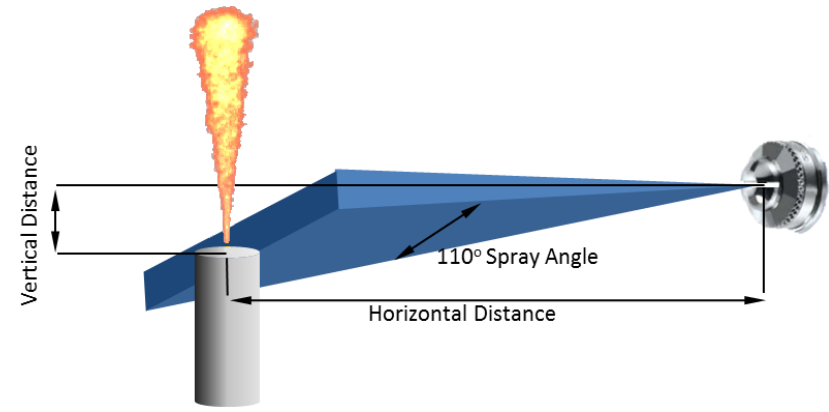

Fig. 5 A schematic of the horizontally-orientated flat fan water mist nozzle.

\subsection{LiB Fire suppression using a horizontal WMFSS}

Having gained an understanding of the fire suppression mechanisms from the Bunsen burner experiments, the horizontal water mist nozzle was used to examine the extinguishment of replica LiB fires. The flat sheet of water mist droplets was injected perpendicularly to the battery, in the orientation as shown in Fig. 5. Propane gas burners are frequently employed by researchers to generate heat to initiate thermal runaway (Ruiz et al. 2018; Feng et al. 2018). Thus, the replica battery was heated by a propane gas burner placed $150 \mathrm{~mm}$ below the replica cell, see Fig. 6 . Heating of the battery leads to exothermic reactions, evaporation of electrolyte and pressure increase inside the cell which eventually bursts the pressure relief vent built into the cap of 18650 cells. To mitigate the risks associated with $\mathrm{LiB}$ fires and the spread of toxic materials, the tests were conducted under a fume hood, inside an enclosure to allow controlled airflow. The enclosure dimensions are $3 \mathrm{~m} \times 3 \mathrm{~m}$ (floor area) $\times 3.1 \mathrm{~m}$ (height). There are $1.1 \mathrm{~m}$ air gaps below each wall to allow airflow into the enclosure. Two LED lights are located at corners of the hood, illuminating the specimen from two sides. A camera with $11 \mathrm{~mm}$ CMOS sensor is also employed with a capture rate of 240 frames per second and resolution of $1080 \mathrm{p}(1920 \times 1080)$. The camera was placed in front of the specimen to record the events.

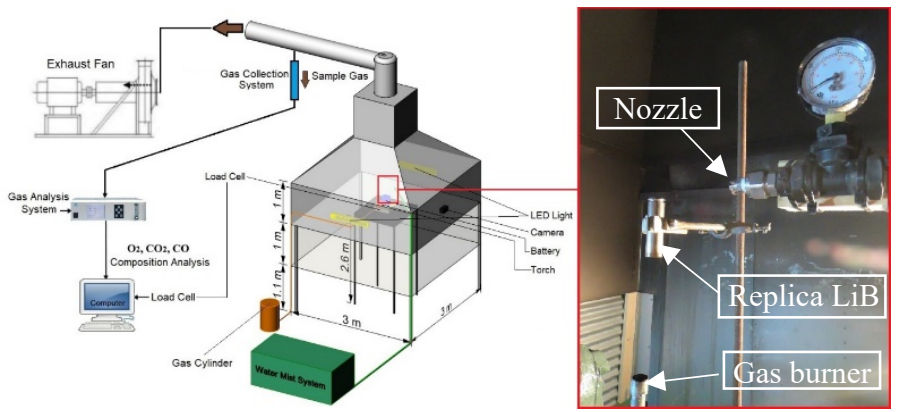

Fig. 6 The experimental apparatus developed for the WMFSS tests. The image shows the set-up of the horizontal water mist nozzle toward the battery and propane gas burner used to heat the replica battery.

The fan nozzle was placed at different horizontal and vertical distances from the top of the battery. The configuration of the nozzle towards the battery and the propane burner can be seen in Fig. 6. The water mist was activated manually at the onset of fire after venting of the electrolyte.

\section{RESULTS}

\subsection{Thermal analysis of electrolyte}

The combustion properties of the electrolyte were determined using a cone calorimeter. Tests were conducted in triplicate to ensure the repeatability of the measurements. The measured HRR of the electrolyte is shown in Fig. 7. The units of HRR have been converted from $\mathrm{kW} / \mathrm{m}^{2}$ to $\mathrm{kW}$, for the comparisons to be made between the experimental and future numerical modelling of battery electrolyte emissions and fire. As can be seen from Fig. 7, it takes approximately 200 seconds to burn 5 grams of electrolyte which is similar to the value reported by Ribiere et al. (Ribière et al. 2012) for a LiB with $0 \%$ state of charge. The HRR increased sharply during the first 20 seconds, with an averaged maximum of $0.54 \mathrm{~kW}$ at approximately 50 seconds after the onset of combustion. The non-uniform HRR profile is due to the different combustion properties of the two electrolyte solvents (discussed in section 2.1); the major contribution to the first peak is the DEC while for the second peak it is the EC. This is consistent with experiments conducted by Eshetu et al. (Eshetu et al. 2014).

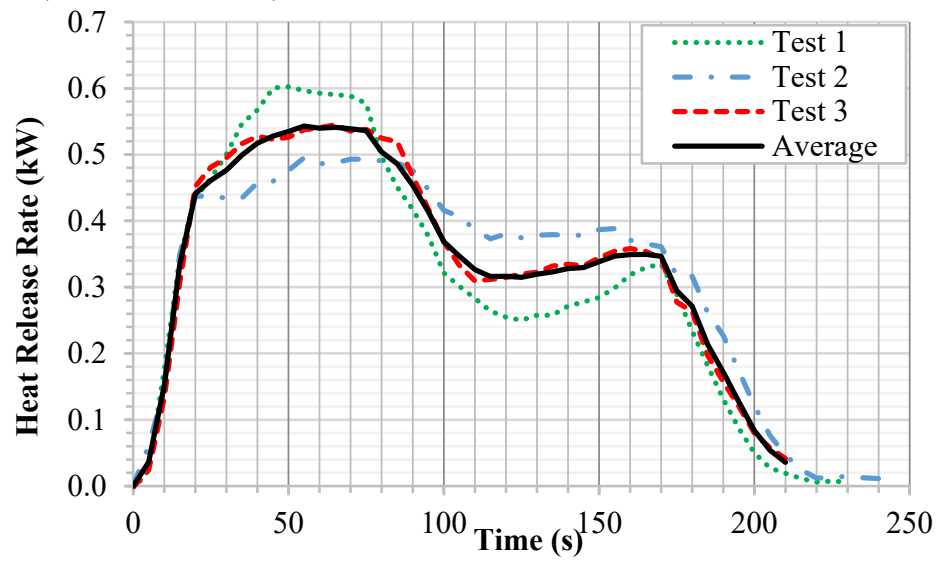

Fig. 7 Heat release rate $(\mathrm{kW})$ of the electrolyte $\left(1.0 \mathrm{M} \mathrm{LiPF}_{6}\right.$ in $\mathrm{EC} / \mathrm{DEC}=50 / 50 \mathrm{v} / \mathrm{v})$ measured using a cone calorimeter 5 grams of electrolyte was poured into a cup and was ignited using a torch. 
The average total heat released (THR) and average effective heat of combustion $\left(\mathrm{EH}_{0} \mathrm{C}\right)$ of the electrolyte are $74.2(\mathrm{~kJ})$ and $15.6(\mathrm{~kJ} / \mathrm{g})$ respectively, shown in Table 2 . THR is calculated as the area under the HRR curve in Fig. 7. The $\mathrm{EH}_{\mathrm{o}} \mathrm{C}$ is obtained by dividing the total heat released by the total mass loss (Babrauskas and Peacock 1992), also presented in Table 2 . The residual mass, predominantly $\mathrm{LiPF}_{6}$, is $0.2 \mathrm{~g}$.

Table 2. Thermal properties of electrolyte revealed by the cone calorimeter.

\begin{tabular}{|c|c|c|c|}
\hline & $\begin{array}{l}\text { Total Mass } \\
\text { Loss }(\mathbf{g})\end{array}$ & $\begin{array}{l}\text { Total Heat } \\
\text { Released (kJ) }\end{array}$ & $\begin{array}{l}\text { Average Effective Heat } \\
\text { of Combustion (kJ/g) }\end{array}$ \\
\hline Test 1 & $4.8 \pm 0.1$ & $71.4 \pm 0.1$ & $15.0 \pm 0.2$ \\
\hline Test 2 & $4.7 \pm 0.1$ & $77.1 \pm 0.1$ & $16.2 \pm 0.2$ \\
\hline Test 3 & $4.8 \pm 0.1$ & $74.1 \pm 0.1$ & $15.6 \pm 0.2$ \\
\hline Average & $\mathbf{4 . 8} \pm 0.2$ & $\mathbf{7 4 . 2} \pm 0.2$ & $\mathbf{1 5 . 6} \pm 0.2$ \\
\hline
\end{tabular}

The average effective heat of combustion of electrolyte $(1.0 \mathrm{M}$ $\mathrm{LiPF}_{6}$ in $\mathrm{EC} / \mathrm{DEC}=50 / 50 \mathrm{v} / \mathrm{v}$ ) is measured as $15.6 \mathrm{~kJ} / \mathrm{g}$ which is in good agreement with the calculated value of $16.6 \mathrm{~kJ} / \mathrm{g}$ based on the effective heat of combustion of EC and DEC measured by Guo et.al (Guo et al. 2019) as 12.15 and $21.06 \mathrm{~kJ} / \mathrm{g}$, respectively.

\subsection{Bunsen burner flame extinguishment using vertical and horizontal water mist}

The effectiveness of a conventional (vertical) water mist system (Fig. 4) in suppressing Bunsen burner flames was investigated by varying the flame length and distance between the water mist nozzle and Bunsen burner tip. The different flame lengths are produced by varying the air/propane gas mixture.

It was observed for all experiments, that a short time after the activation of the WMFSS (once a full mist spray had been established), a flame lift-off zone (the distance between the Bunsen burner tip and the base of the flame) developed. This phenomenon is most likely the result of entrainment of water mist into the combustion zone at the base of the flame, cooling and diluting the propane/air mixture. The extinguishing results of these Bunsen burner tests are presented in Table 3 and indicate that shorter flame lengths or shorter vertical distances between the burner and nozzle produced faster extinguishing times. The shorter $80 \mathrm{~mm}$ flames burn closer to the ideal stoichiometric fuel/air ratio; there is less excess fuel. Also, geometries with the water mist in closer proximity to the fuel source result in higher water flux reaching the fuel source. Conversely, as the vertical distance or flame length increased, extinguishment time became longer. Longer flames produced by the Bunsen burner have a higher fuel mass flow rate which requires larger quantities of water to absorb the heat.

Table 3. Effect of Bunsen burner flame lengths and distances between the nozzle and burner tip on the extinguishment time for the conventional vertical WMFSS. The flame lengths are measured using image postprocessing. NA indicates that extinguishment is Not Achieved.

\begin{tabular}{|c|c|c|c|}
\hline \multirow{2}{*}{$\begin{array}{l}\text { Vertical } \\
\text { Distance } \\
(\mathrm{mm})\end{array}$} & \multicolumn{3}{|c|}{ Extinguishment Time (s) } \\
\hline & $\begin{array}{l}\text { Flame Length } \\
=80(\mathrm{~mm})\end{array}$ & $\begin{array}{l}\text { Flame Length } \\
=140(\mathrm{~mm})\end{array}$ & $\begin{array}{l}\text { Flame Length } \\
=200(\mathrm{~mm})\end{array}$ \\
\hline 160 & $1 \pm 1$ & $1 \pm 1$ & $33 \pm 1$ \\
\hline 190 & $1 \pm 1$ & $1 \pm 1$ & $50 \pm 1$ \\
\hline 220 & $1 \pm 1$ & $6 \pm 1$ & $98 \pm 1$ \\
\hline 250 & $1 \pm 1$ & $23 \pm 1$ & $105 \pm 1$ \\
\hline 280 & $1 \pm 1$ & $78 \pm 1$ & $129 \pm 1$ \\
\hline 310 & $1 \pm 1$ & NA & NA \\
\hline 340 & $1 \pm 1$ & NA & NA \\
\hline 370 & $2 \pm 1$ & NA & NA \\
\hline 400 & $3 \pm 1$ & NA & NA \\
\hline
\end{tabular}

Additionally, it was observed that the water mist interaction with longer flames produced erratic behavior where the flame diminished in size and morphed into unusual geometries above the lift-off zone, virtually extinguishing, then would restabilize, as water was entrained into the combustion at fluctuating rates as a reaction to the flame behavior. This phenomenon may be partially due to the fire enclosure and will not be explored further here: rather it is the lift-off zone behavior that is of further interest.

For the horizontal water mist application, extinguishment of Bunsen burner flames for the flame lengths used in Table 3 was repeated. This time the fan nozzle distance from the Bunsen burner was adjusted vertically and horizontally (refer to Fig. 5). Again, the lift-off zone increased after the activation of the water mist, as a result of water droplets within the combustion zone, and this distance varied depending on the flame length. Rapid flame extinguishment occurred at approximately 1-3 seconds (i.e. immediately after the water mist reached the burner) with flame lengths of $80 \mathrm{~mm}$ and $140 \mathrm{~mm}$ (producing flame lift-off zones smaller than $5 \mathrm{~mm}$ ) for vertical and horizontal distances up to $50 \mathrm{~mm}$ and $400 \mathrm{~mm}$, respectively. However, the fire extinguishment for a flame length of $200 \mathrm{~mm}$, producing a flame lift-off zone of $20 \mathrm{~mm}$, depended on both the horizontal and vertical distances, these are presented in Table 4 and Fig. 8.

Table 4. Fire extinguishment time (s) using the horizontal WMFSS at different nozzle vertical and horizontal distances $(\mathrm{mm})$ from the top of the burner with the flame length of $200 \mathrm{~mm}$. NA indicates that extinguishment is Not Achieved.

\begin{tabular}{|l|l|l|l|l|l|l|l|l|}
\hline \multirow{2}{*}{$\begin{array}{l}\text { Vertical } \\
\text { Distance } \\
\text { (mm) }\end{array}$} & \multicolumn{7}{|l|}{ Horizontal Distance $(\mathbf{m m}) \pm 2$} \\
\hline 10 & $1 \pm 1$ & $1 \pm 1$ & $1 \pm 1$ & $2 \pm 1$ & $2 \pm 1$ & $2 \pm 1$ & NA & NA \\
\hline 20 & $1 \pm 1$ & $1 \pm 1$ & $1 \pm 1$ & $2 \pm 1$ & $2 \pm 1$ & NA & NA & NA \\
\hline 30 & NA & NA & NA & $2 \pm 1$ & $2 \pm 1$ & $2 \pm 1$ & $3 \pm 1$ & $3 \pm 1$ \\
\hline 40 & NA & NA & NA & NA & $2 \pm 1$ & $2 \pm 1$ & $3 \pm 1$ & $3 \pm 1$ \\
\hline 50 & NA & NA & NA & NA & NA & NA & NA & $3 \pm 1$ \\
\hline 60 & NA & NA & NA & NA & NA & NA & NA & NA \\
\hline
\end{tabular}

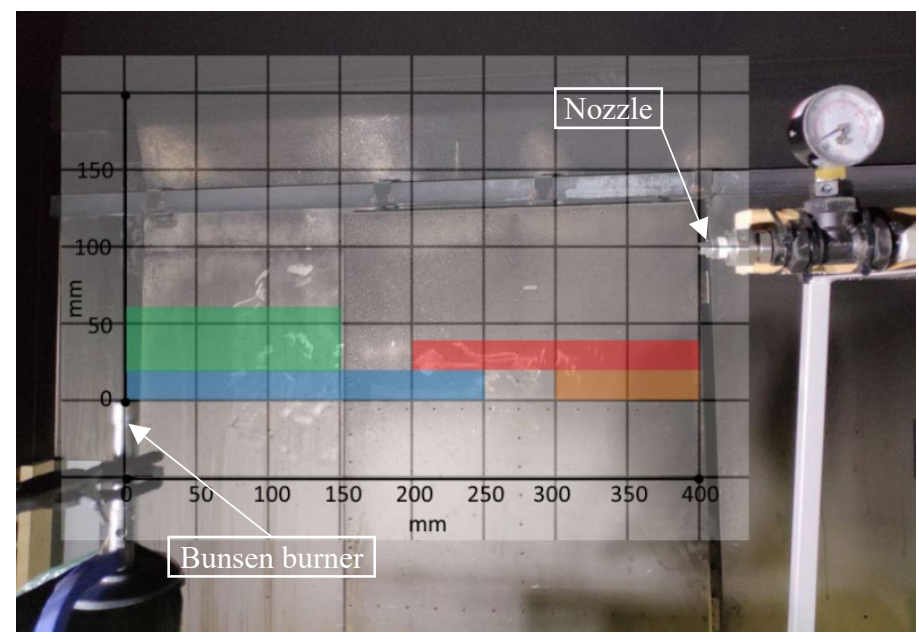

Fig. 8 Results from Table 4 for the Bunsen burner flame length of 200 $\mathrm{mm}$, are superimposed over the horizontal water mist geometry to visualize the extinguishment zones. The image depicts the nozzle at a horizontal distance of $400 \mathrm{~mm}$ and a vertical distance of $100 \mathrm{~mm}$ from the Bunsen burner.

At vertical distances greater than $20 \mathrm{~mm}$ and horizontal distances of $150 \mathrm{~mm}$ or less (the green area), the water mist was unable to extinguish the flames. At these vertical distances, the main water mist sheet passes 
through the flame, cooling the flame rather than passing through the flame lift-off zone and cooling/diluting the gas mixture.

At vertical distances 30 and $40 \mathrm{~mm}$ and horizontal distances 200 $\mathrm{mm}$ and greater (the red area), the mist droplets produce extinguishment. At these vertical and horizontal distances, the mist sheet curves downward into the flame lift-off zone, producing gas cooling and dilution at the base of the flame resulting in suppression. As the vertical distance is increased, the mist droplets no longer pass through the lift-off zone. It can be concluded that the horizontal WMFSS could suppress the Bunsen burner flame if the water mist passes through the lift-off zone.

\subsection{LiB fire extinguishment using the horizontal WMFSS}

The horizontal mist spray was applied to fires produced by single replica LiBs. The replica batteries were heated from below with a propane flame, inducing electrolyte venting. When ignition occurred, the water mist system was activated. Fig. 9 shows an example of the various stages of a replica LiB fire and interaction with the horizontal WMFSS located at $70 \mathrm{~mm}$ vertical and $400 \mathrm{~mm}$ horizontal from the top of the LiB. The short flame lift-off zone observed in Fig. 9c) extends on the activation of water mist and appears to reach approximately $65 \mathrm{~mm}$ in Fig. 9e) before extinguishment. It should be noted that, for an unsuppressed LiB fire, toward the end of the battery venting process, the speed of the outgoing gases decreases and combustion changes from a jet fire to a diffusion flame and the flames emanate from the top of the battery without a flame lift-off zone.

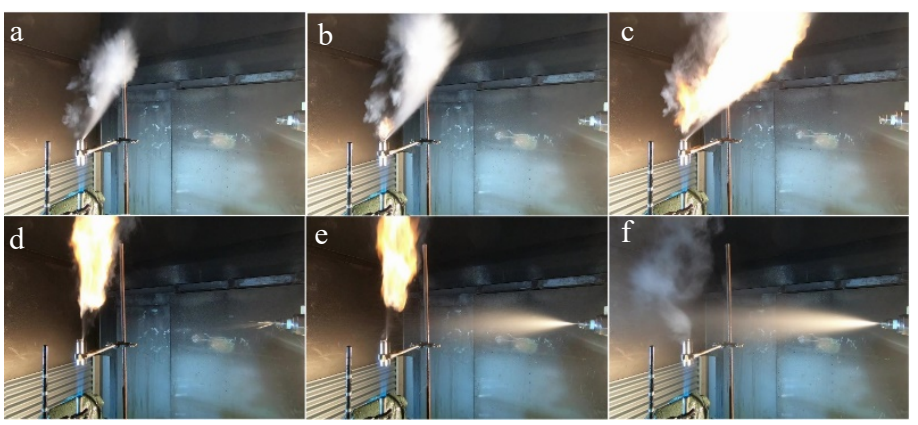

Fig. 9 Images show the evolution of the replica battery fire extinguishment exposed to horizontal water mist positioned at $70 \mathrm{~mm}$ and $400 \mathrm{~mm}$ vertical and horizontal distances respectively. a) the flammable gas (electrolyte vapor) venting; b) onset of fire; c) fire development; d) activation of the WMFSS; e) interaction of the water mist and fire; and f) fire extinguishment.

The effect of varying the vertical and horizontal distances between the water mist nozzle and the top of the replica LiB are presented in Table 5 and Fig. 10. The results show that immediate flame suppression on activation is achieved for vertical distances less than $70 \mathrm{~mm}$. The vertical distance appears to be the critical factor in this technique, while there is no change in extinguishing behavior up to the maximum tested horizontal length of $400 \mathrm{~mm}$. The mechanism associated with fire extinguishment appears to be similar to the Bunsen burner flame extinguishment, water mist droplets moving into the combustion zone. At vertical distances of $80 \mathrm{~mm}$ and above, the majority of the water droplets have passed through the flame rather than the lift-off zone at the base of the flame and extinguishment did not occur. The successful extinguishments at $70 \mathrm{~mm}$ vertical distance and greater than $100 \mathrm{~mm}$ horizontal distance (just above the lift-off zone) will be due to the effects of gravity; the droplets falling from the horizontal axis into the lift-off zone. The non-extinguishment at $70 \mathrm{~mm}$ vertical and $100 \mathrm{~mm}$ horizontal distance is likely to be due to the momentum of the water mist droplets being too large to allow entrainment into the combustion zone at the base of the flame so that the cooling and gas dilution did not occur.
Table 5. Fire extinguishment time (s) using the horizontal WMFSS at different nozzle vertical and horizontal distances from the top of the replica LiB. NA indicates that extinguishment is Not Achieved.

\begin{tabular}{|c|c|c|c|c|}
\hline $\begin{array}{c}\text { Vertical } \\
\text { Distance }(\mathbf{m m})\end{array}$ & \multicolumn{4}{|c|}{ Horizontal Distance (mm) \pm 2} \\
\cline { 2 - 5 } & $\mathbf{1 0 0}$ & $\mathbf{2 0 0}$ & $\mathbf{3 0 0}$ & $\mathbf{4 0 0}$ \\
\hline 10 & $1 \pm 1$ & $1 \pm 1$ & $2 \pm 1$ & $2.5 \pm 1$ \\
\hline 20 & $1 \pm 1$ & $1 \pm 1$ & $2 \pm 1$ & $2.5 \pm 1$ \\
\hline 30 & $1 \pm 1$ & $1 \pm 1$ & $2 \pm 1$ & $2.5 \pm 1$ \\
\hline 40 & $1 \pm 1$ & $1 \pm 1$ & $2 \pm 1$ & $2.5 \pm 1$ \\
\hline 50 & $1.5 \pm 1$ & $1.5 \pm 1$ & $2.5 \pm 1$ & $3 \pm 1$ \\
\hline 60 & $2 \pm 1$ & $2 \pm 1$ & $3 \pm 1$ & $3.5 \pm 1$ \\
\hline 70 & NA & $2.5 \pm 1$ & $4 \pm 1$ & $5 \pm 1$ \\
\hline 80 & NA & NA & NA & NA \\
\hline 90 & NA & NA & NA & NA \\
\hline 100 & NA & NA & NA & NA \\
\hline
\end{tabular}

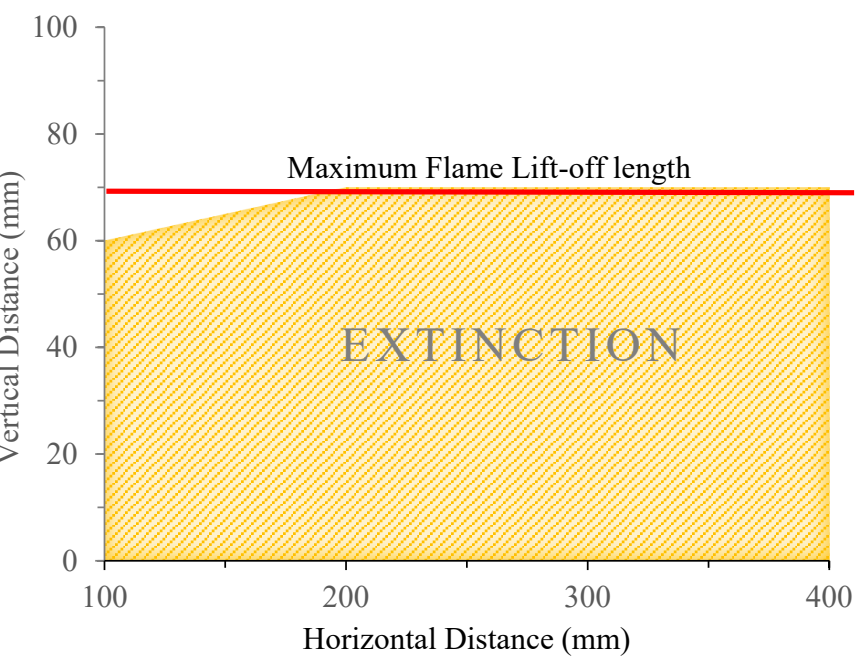

Fig. 10 The nozzle-to-flame configurations producing effective suppression by the horizontal WMFSS for different nozzle vertical and horizontal distances from the top of the replica LiB.

It is worth noting that the two WMFSS (vertical and horizontal) examined are quite different in terms of nozzle type and flow rate, due to the reasons explained previously, thus it makes a direct comparison on the efficacy of the systems difficult. The investigation into the efficacy of vertical and horizontal WMFSS with the same flow rates is the subject of future research. However, the dominant mechanisms involved in both systems of water mist suppression of Bunsen burner and replica LiB fires are thought to be:

1. Cooling; reducing the heat feedback from the flame to the gas mixture exiting the Bunsen burner and replica LiB to a level below that required for the flame to be sustained;

2. Dilution of the gas preheat zone primarily by water vapor. This mechanism has the potential of reducing the gas concentration below its Lower Flammability Limit.

Water mist can also provide cooling to the battery after the electrolyte combustion has been extinguished, potentially providing control of thermal runaway and reducing the likelihood of cascading heat transfer to adjoining cells.

In summary, it can be seen that water mist can extinguish a LiB fire by passing through the lift-off zone. For a real LiB, if the battery surface is not sufficiently cooled at the end of water mist application, the internal reactions of the cell will not be interrupted and the $\mathrm{LiB}$ is likely to reignite or even cause the thermal runaway of the adjacent battery. Spraying water mist directly on the surface of the cell can effectively cool the cell and inhibit the internal reactions (Wang et al. 2019). Thus, there is a 
nozzle position that allows the droplets to pass through the lift-off zone and maintain a large contact area with the surface of the cell (through droplets falling from the horizontal axis due to gravity), which provides the best extinguishing and cooling effect. This is of practical significance for real $\mathrm{LiB}$ fires and determining the optimum position will be addressed in future studies.

\section{CONCLUSIONS}

Lithium-ion batteries pose significant fire risks and the development of fire extinguishment systems for LiBs has not been sufficiently established to provide a satisfactory level of security in the event of a fire. This paper highlights that water mist may be an effective method of extinguishment of LiB fires.

A water mist fire suppression technique has been introduced to suppress LiB fires. In this technique, water droplets are produced by a fan nozzle and sprayed horizontally toward the flames of a replica 18560 $\mathrm{LiB}$. The water droplets are entrained into the gas mixture at the base of the flames, cooling the gas and depleting the oxygen concentration. This horizontal water mist fire suppression technique has been tested at different vertical and horizontal distances to highlight the mechanisms associated with water droplets interacting with fires. The results show fires are suppressed rapidly on activation of the WMFSS for geometries that enable the water mist direct access to the lift-off zone, between the gas source and base of the flame. Further investigation of water mist to provide cooling for the control of thermal runaway reactions and cascading heat transfer to adjacent LiBs is recommended. Additionally, having characterized the thermal behavior of the electrolyte, this information can be used to validate numerical simulations of $\mathrm{LiB}$ fire and suppression.

\section{ACKNOWLEDGEMENTS}

This work was supported by the Defence Science and Technology, Department of Defence, Australia and Victoria University.

\section{REFERENCES}

Arora, Pankaj, and Zhengming Zhang. 2004. 'Battery separators', Chemical reviews, 104: 4419-62. https://doi.org/10.1021/cr020738u

Babrauskas, Vytenis, Daniel T Gottuk, John R Hall Jr, Kazunori Harada, Erica D Kuligowski, Milosh Puchovsky, John M Watts Jr, and Christopher J Wieczorek. 2015. The Cone Calorimeter (Springer). https://doi.org/10.1007/978-1-4939-2565-0

Babrauskas, Vytenis, and Richard D Peacock. 1992. 'Heat release rate: the single most important variable in fire hazard', Fire Safety Journal, 18: 255-72. https://doi.org/10.1016/0379-7112(92)90019-9

Blum, Andrew F, and R Thomas Long Jr. 2016. Fire Hazard Assessment of Lithium Ion Battery Energy Storage Systems (Springer). https://doi.org/10.1007/978-1-4939-6556-4

Depetro, Aidan. 2016. 'Future Submarine Fire Safety Study', Victoria University.

Ditch, Benjamin, and Jaap De Vries. 2013. Flammability characterization of lithium-ion batteries in bulk storage (FM Global).

Egelhaaf, Markus, David Kress, Dieter Wolpert, Thomas Lange, Rainer Justen, and Hartung Wilstermann. 2013. 'Fire Fighting of Li-Ion Traction Batteries', SAE International Journal of Alternative Powertrains, 2: 3748. https://doi.org/10.4271/2013-01-0213

Eshetu, Gebrekidan Gebresilassie, Jean-Pierre Bertrand, Amandine Lecocq, Sylvie Grugeon, Stephane Laruelle, Michel Armand, and Guy Marlair. 2014. 'Fire behavior of carbonates-based electrolytes used in Liion rechargeable batteries with a focus on the role of the LiPF6 and LiFSI salts', Journal of Power Sources, 269: 804-11. https://doi.org/10.1016/j.jpowsour.2014.07.065

Feng, Xuning, Minggao Ouyang, Xiang Liu, Languang Lu, Yong Xia, and Xiangming He. 2018. 'Thermal runaway mechanism of lithium ion battery for electric vehicles: A review', Energy Storage Materials, 10: 246-67. https://doi.org/10.1016/j.ensm.2017.05.013

Galatro, Daniela, Maan Al-Zareer, Carlos Da Silva, David Romero, Cristina \%J Frontiers in Heat Amon, and Mass Transfer. 2020. 'Thermal behavior of lithium-ion batteries: aging, heat generation, thermal management and failure', 14. https://doi.org/10.5098/hmt.14.17

Ghiji, Matt, Shane Edmonds, and Khalid \%J Applied Sciences Moinuddin. 2021. 'A Review of Experimental and Numerical Studies of $\begin{array}{lllll}\text { Lithium Ion } & \text { Battery }\end{array}$ https://doi.org/10.3390/app11031247

Ghiji, Mohammadmahdi, Vasily Novozhilov, Khalid Moinuddin, Paul Joseph, Ian Burch, Brigitta Suendermann, and Grant. J Energies Gamble. 2020. 'A Review of Lithium-Ion Battery Fire Suppression', 13: 5117. https://doi.org/10.3390/en13195117

Guo, Feng, Yu Ozaki, Katsunori Nishimura, Nozomu Hashimoto, Osamu J Combustion Fujita, and Flame. 2019. 'Experimental study on flame stability limits of lithium ion battery electrolyte solvents with organophosphorus compounds addition using a candle-like wick $\begin{array}{lll}\text { combustion } \quad \text { system', } & \text { 63-70. }\end{array}$ https://doi.org/10.1016/j.combustflame.2019.05.019

Guo, L. S., Z. R. Wang, J. H. Wang, Q. K. Luo, and J. J. Liu. 2017. 'Effects of the environmental temperature and heat dissipation condition on the thermal runaway of lithium ion batteries during the chargedischarge process', Journal of Loss Prevention in the Process Industries, 49: 953-60. https://doi.org/10.1016/j.jlp.2017.05.029

Hill, Davion. 2017. "Considerations for Energy Storage Systems (ESS) Fire Safety." In. Dublin, OH, U.S.A: Det Norske Veritas (U.S.A.), Inc. (DNV GL).

Julien, Christian, Alain Mauger, Ashok Vijh, and Karim Zaghib. 2016. 'Lithium batteries.' in, Lithium Batteries (Springer). https://doi.org/10.1007/978-3-319-19108-9_2

Karpov, A, V Bulgakov, A Galat, and VB Novozhilov. 2004. "Numerical Modeling of Water Mist Suppression of Small Scale Flame Spreading over Solid Combustibles." In Sixth Asia-Oceania Symposium on Fire Science and Technology, 922-34. https://doi.org/10.3801/iafss.fss.8-753

Kong, Lingxi, Chuan Li, Jiuchun Jiang, and Michael G J Energies Pecht. 2018. 'Li-ion battery fire hazards and safety strategies', 11: 2191. https://doi.org/10.3390/en11092191

Lamb, Joshua, Christopher J. Orendorff, Leigh Anna M. Steele, and Scott W. Spangler. 2015. 'Failure propagation in multi-cell lithium ion batteries', Journal of Power Sources, 283: 517-23. https://doi.org/10.1016/i.jpowsour.2014.10.081

Larsson, Fredrik. 2017. 'Lithium-ion Battery Safety-Assessment by Abuse Testing, Fluoride Gas Emissions and Fire Propagation', Chalmers University of Technology.

Larsson, Fredrik, Petra Andersson, Per Blomqvist, Anders Lorén, and Bengt-Erik Mellander. 2014. 'Characteristics of lithium-ion batteries during fire tests', Journal of Power Sources, 271: 414-20. https://doi.org/10.1016/j.jpowsour.2014.08.027

Larsson, Fredrik, Petra Andersson, and Bengt-Erik Mellander. 2016. 'Lithium-ion battery aspects on fires in electrified vehicles on the basis of experimental abuse tests', Batteries, 2: 9. https://doi.org/10.3390/batteries2020009 
Larsson, Fredrik, Simon Bertilsson, Maurizio Furlani, Ingvar Albinsson, and Bengt-Erik Mellander. 2018. 'Gas explosions and thermal runaways during external heating abuse of commercial lithium-ion graphiteLiCoO2 cells at different levels of ageing', Journal of Power Sources, 373: 220-31. https://doi.org/10.1016/j.jpowsour.2017.10.085

Li, Y, D Yu, S Zhang, Q Hu, X Liu, and J Wang. 2015. 'On the fire extinguishing tests of typical lithium ion battery', Journal of Safety and Environment, 15: 120-25.

Liu, Yujun, Qiangling Duan, Jiajia Xu, Haodong Chen, Wei Lu, and Qingsong Wang. 2018. 'Experimental study on the efficiency of dodecafluoro-2-methylpentan-3-one on suppressing lithium-ion battery fires', RSC advances, 8: 42223-32. https://doi.org/10.1039/c8ra08908f

Long, Richard Thomas, Andrew F Blum, Thomas J Bress, and Benjamin RT Cotts. 2013. "Best practices for emergency response to incidents involving electric vehicles battery hazards: A report on full-scale testing results." In. Quincy, Massachusetts, U.S.A.: National Fire Protection Research Foundation.

Luo, Wei-tao, Shun-bing Zhu, Jun-hui Gong, and Zheng Zhou. 2018. 'Research and development of fire extinguishing technology for power lithium batteries', Procedia engineering, 211: 531-37. https://doi.org/10.1016/j.proeng.2017.12.045

Maloney, Thomas. 2014. "Extinguishment of lithium-ion and lithiummetal battery fires." 46-51. Washington, DC, USA.: US Federal Aviation Administration.

Mawhinney, JR, BZ Dlugogorski, and AK Kim. 1994. 'A closer look at the fire extinguishing properties of water mist', Fire Safety Science, 4: 47-60. https://doi.org/10.3801/iafss.fss.4-47

Novozhilov, V. 2003. 'Some aspects of the mathematical modelling of fireballs', Proceedings of the Institution of Mechanical Engineers, Part E: Journal of Process Mechanical Engineering, 217: 103-21. https://doi.org/10.1243/095440803766612775

Ouyang, Dongxu, Mingyi Chen, Que Huang, Jingwen Weng, Zhi Wang, and Jian Wang. 2019. 'A Review on the Thermal Hazards of the LithiumIon Battery and the Corresponding Countermeasures', Applied Sciences, 9: 2483. https://doi.org/10.3390/app9122483

Pacala, Stephen, and Robert Socolow. 2004. 'Stabilization wedges: solving the climate problem for the next 50 years with current technologies', science, 305: 968-72. https://doi.org/10.1126/science.1100103

Ping, Ping, QingSong Wang, PeiFeng Huang, Ke Li, JinHua Sun, DePeng Kong, and ChunHua Chen. 2015. 'Study of the fire behavior of high-energy lithium-ion batteries with full-scale burning test', Journal of Power Sources, 285: 80-89. https://doi.org/10.1016/j.jpowsour.2015.03.035

Prasad, K, C Li, and K Kailasanath. 1998a. "Numerical Modeling of Fire Suppression Using Water Mist. 2. An Optimization Study on Jet Diffusion Flames." In.: Naval Research Lab Washington Dc Center for Reactive Flow and Dynamical Systems. https://doi.org/10.21236/ada349379

Prasad, Kuldeep, Chiping Li, and K Kailasanath. 1998b. "Optimizing water-mist injection characteristics for suppression of coflow diffusion flames." In Symposium (International) on Combustion, 2847-55. Elsevier. https://doi.org/10.1016/s0082-0784(98)80143-4

Rao, Hui, Zhaoxia Huang, Hui Zhang, and Shuming Xiao. 2015. "Study of fire tests and fire safety measures on lithiumion battery used on ships." In 2015 International Conference on Transportation Information and Safety (ICTIS), 865-70. IEEE. https://doi.org/10.1109/ictis.2015.7232158
Reaction-To-Fire Tests; Heat Release, Smoke Production and Mass Loss Rate." In. 2015. ISO 5660, International Standard. Geneva: International Organization for Standardization, ISO/TC 92/SC 1 Fire initiation and growth. https://doi.org/10.3403/bsiso5660

Ribière, Perrine, Sylvie Grugeon, Mathieu Morcrette, Simeon Boyanov, Stéphane Laruelle, and Guy Marlair. 2012. 'Investigation on the fireinduced hazards of Li-ion battery cells by fire calorimetry', Energy \& Environmental Science, 5: 5271-80. https://doi.org/10.1039/c1ee02218k

Rodriguez, Branelle R. 2013. "Development of the International Space Station (ISS) Fine Water Mist (FWM) Portable Fire Extinguisher." In 43rd International Conference on Environmental Systems, 3413.

Ruiz, V., A. Pfrang, A. Kriston, N. Omar, P. Van den Bossche, and L. Boon-Brett. 2018. 'A review of international abuse testing standards and regulations for lithium ion batteries in electric and hybrid electric vehicles', Renewable and Sustainable Energy Reviews, 81: 1427-52. https://doi.org/10.1016/j.rser.2017.05.195

Singh, Randeep, Gero Lapp, Jason Velardo, Phan Thanh Long, Masataka Mochizuki, Aliakbar Akbarzadeh, Karsten Mausolf, Kristin J Frontiers in Heat Busse, and Mass Transfer. 2021. 'battery Cooling Options in Electric Vehicles with Heat Pipes', 16. https://doi.org/10.5098/hmt.16.2

Summer, Steven M. 2010. Flammability assessment of lithium-ion and lithium-ion polymer battery cells designed for aircraft power usage (US Department of Transportation, Federal Aviation Administration).

Tarascon, J-M, and Michel Armand. 2001. 'Issues and challenges facing rechargeable lithium batteries', Nature, 414: 359-67. https://doi.org/10.1038/35104644

Wang, Qingsong, Peifeng Huang, Ping Ping, Yulong Du, Ke Li, and Jinhua Sun. 2017. 'Combustion behavior of lithium iron phosphate battery induced by external heat radiation', Journal of Loss Prevention in the Process Industries, 49: 961-69. https://doi.org/10.1016/j.jlp.2016.12.002

Wang, Qingsong, Binbin Mao, Stanislav I. Stoliarov, and Jinhua Sun. 2019. 'A review of lithium ion battery failure mechanisms and fire prevention strategies', Progress in Energy and Combustion Science, 73: 95-131. https://doi.org/10.1016/j.pecs.2019.03.002

Wang, Qingsong, Ping Ping, Xuejuan Zhao, Guanquan Chu, Jinhua Sun, and Chunhua Chen. 2012. 'Thermal runaway caused fire and explosion of lithium ion battery', Journal of Power Sources, 208: 210-24. https://doi.org/10.1016/j.jpowsour.2012.02.038

Wang, Qingsong, Guangzheng Shao, Qiangling Duan, Man Chen, Yongqi Li, Ke Wu, Bangjin Liu, Peng Peng, and Jinhua Sun. 2016. 'The efficiency of heptafluoropropane fire extinguishing agent on suppressing the lithium titanate battery fire', Fire technology, 52: 387-96. https://doi.org/10.1007/s10694-015-0531-9

Wilkens, Konrad, Bjarne Johnsen, Abhishek Bhargava, and Anders Dragsted. 2017. "Assessment of existing fire protection strategies and recommendation for future work." In Project BLUE BATTERY, Part II. Denmark: Danish Institute of Fire and security Technology.

Ye, Jiana, Haodong Chen, Qingsong Wang, Peifeng Huang, Jinhua Sun, and Siuming Lo. 2016. 'Thermal behavior and failure mechanism of lithium ion cells during overcharge under adiabatic conditions', Applied energy, 182: 464-74. https://doi.org/10.1016/j.apenergy.2016.08.124

Zheng, Li Gang, Ming Gao Yu, Shui Jun Yu, and Chang Lu. 2011. 'Measurement of Flame Height by Image Processing Method', Advanced Materials Research, 301-303: 983-88. https://doi.org/10.4028/www.scientific.net/amr.301-303.983 